06, 1;07.3

\title{
Лазерно-индуцированный графен на полиимидной пленке: наблюдение эффекта увлечения
}

\author{
(ㄱ К.Г. Михеев, Р.Г. Зонов, Д.Л. Булатов, А.Е. Фатеев, Г.М. Михеев \\ Институт механики, Удмуртский федеральный исследовательский центр УрО РАН, Ижевск, Россия \\ E-mail: k.mikheev@udman.ru
}

Поступило в Редакцию 12 декабря 2019 г.

В окончательной редакции 12 декабря 2019 г.

Принято к публикации 18 февраля 2020 г.

\begin{abstract}
При воздействии сфокусированного излучения непрерывного $\mathrm{CO}_{2}$-лазера на полиимидную пленку получены пленочные структуры, состоящие из пористого графена. В полученных структурах наблюдалась генерация наносекундных импульсов фототока, возникающих под действием наносекундных лазерных импульсов в широком диапазоне длин волн. Показано, что фототок линейно возрастает при увеличении импульсной лазерной мощности и зависит от угла падения света на пленочную структуру по закону нечетной функции. Измерена зависимость коэффициента преобразования лазерной мощности в фототок от длины волны света. Полученные результаты объясняются генерацией фототока за счет эффекта увлечения.
\end{abstract}

Ключевые слова: лазерно-индуцированный графен, фототок, эффект увлечения.

DOI: 10.21883/PJTF.2020.09.49375.18152

В настоящее время имеется большое число работ, посвященных синтезу графена и его производных. Наиболее продвинутым методом формирования графена с точки зрения получения заданного количества монослоев, однородности и сплошности является метод химического осаждения из газовой фазы (CVD) [1,2]. Однако этот метод получения графена является дорогостоящим для применения в промышленных масштабах. Недавно в работе [3] была продемонстрирована возможность получения пористого графена (3D-графена), названного лазерно-индуцированным графеном (ЛИГ), методом разложения полимерной пленки с помощью импульснопериодического излучения $\mathrm{CO}_{2}$-лазера с длительностью импульсов $14 \mu \mathrm{s}$ в воздушной атмосфере при обычных условиях. Изобретенный метод является весьма простым в реализации и позволяет за короткое время формировать на поверхности углеродсодержащего материала 3D-графен произвольной площади в виде произвольных фигур. В дальнейших работах ЛИГ был получен с применением $\mathrm{CO}_{2}$-лазеров, генерирующих импульснопериодическое излучение с различной длительностью импульсов [4,5], с помощью фемтосекундных лазерных импульсов, следующих с частотой повторений $1 \mathrm{MHz}$, на длине волны $522 \mathrm{~nm}$ [6], а также с помощью непрерывного излучения полупроводникового лазера на длине волны $405 \mathrm{~nm}$ [7]. К настоящему времени показана перспективность использования ЛИГ для различных приложений [8] (например, для изготовления микросуперконденсаторов, различных датчиков, электрокатализаторов и микрофлюидных систем). Между тем известно, что в графене и нанографитных пленках можно наблюдать фототок $[9,10]$ эффекта увлечения (ЭУ) [11], зависящий от угла падения света на пленку по нечетному закону (см., например, [12-14]). Однако, насколько нам извест- но, публикации, посвященные исследованию генерации фототока в ЛИГ, отсутствуют. Целью настоящей работы являются наблюдение и исследование ЭУ в ЛИГ, полученном на поверхности полиимидной пленки с помощью непрерывного $\mathrm{CO}_{2}$-лазера.

В наших экспериментах для синтеза ЛИГ применялись коммерческие полиимидные пленки толщиной $40,80,120 \mu \mathrm{m}$ и $\mathrm{CO}_{2}$-лазер на длине волны $10.6 \mu \mathrm{m}$, генерирующий непрерывное излучение мощностью до $50 \mathrm{~W}$ (имелась возможность плавно ее варьировать). Измерение мощности лазера проводилось с помощью прибора PM100D с измерительной головкой S425C-L (Thorlabs). Формирование ЛИГ осуществлялось при построчном сканировании сфокусированным пучком лазера на автоматизированном столике по заданной программе в воздушной атмосфере. При этом лазерный пучок фокусировался с помощью линзы с фокусным расстоянием $51 \mathrm{~mm}$ на поверхность полиимидной пленки. Диаметр сфокусированного пучка на пленке, измеренный хорошо известным методом „острого края“, составлял $190 \mu \mathrm{m}$. Для нахождения оптимальных условий получения ЛИГ в экспериментах варьировались мощность лазера и скорость сканирования. Идентификация ЛИГ в полученных пленках осуществлялась с помощью спектрометра комбинационного рассеяния света (КРС) Horiba HR800 с возбуждающим излучением на длине волны $632.8 \mathrm{~nm}$. Морфология полученных пленок исследовалась с помощью сканирующего электронного микроскопа Leo 1550 Gemini (Zeiss). Поверхностное сопротивление синтезированных пленок измерялось четырехзондовым методом.

Для исследования генерации фототока полученные пленки располагались на специальном гониометрическом устройстве, позволяющем плавно изменять угол 


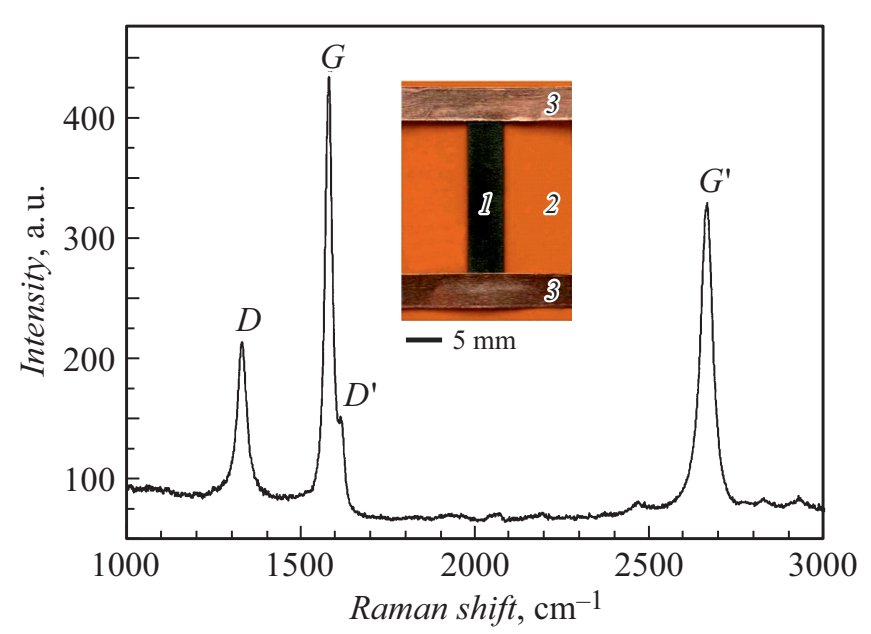

Рис. 1. Спектр комбинационного рассеяния света лазерноиндуцированного графена. На вставке - фотография лазерноиндуцированного графена (1) на полиимидной пленке (2) с электродами (3).

падения света $\alpha$ на пленку. Вдоль коротких сторон к пленке прикреплялись измерительные электроды (рис. 1, вставка), которые с помощью коаксиального кабеля непосредственно подсоединялись к цифровому осциллографу Tektronix TDS7704B с полосой пропускания $7 \mathrm{GHz}$. Генерация фототока в синтезированных пленках исследовалась при их облучении излучением первой, второй, третьей и четвертой гармоник одномодового YAG : $\mathrm{Nd}^{3+}$-лазера с пассивной модуляцией добротности [15] на длинах волн $\lambda_{\text {in }}=1064,532,354.7$ и $266 \mathrm{~nm}$ соответственно. Длительности лазерных импульсов $\tau_{\text {in }}$ (по полувысоте) измерялись с помощью быстродействующего фотоприемника SIR-5 (Thorlabs) и цифрового осциллографа. Энергии $E_{\text {in }}$ наносекундных лазерных импульсов, падающих на исследуемые пленки, измерялись с помощью пироэлектрического измерителя энергии ES111 через интерфейс PM100USB (Thorlabs). В экспериментах измерялись экстремальные значения импульсов напряжения $U_{x}$ и длительности $\tau$ (по полувысоте) одиночных импульсов фотоэдс наносекундной длительности, возникающих между измерительными электродами при наклонном облучении синтезированной пленки. Продольный фототок $i_{x}$ (далее фототок), протекающий в направлении, параллельном плоскости падения $[13,14]$, определялся по формуле $i_{x}=U_{x} / r$, где $r$ - входное сопротивление осциллографа.

Эксперименты показали, что оптимальными для получения ЛИГ являются следующие параметры лазера: плотность мощности $8 \mathrm{~W} / \mathrm{cm}^{2}$, скорость сканирования $255 \mathrm{~mm} / \mathrm{s}$. На рис. 1 (вставка) показана фотография синтезированной пленки в форме прямоугольника размером $5 \times 20 \mathrm{~mm}$. Поверхностное электрическое сопротивление пленки составляет $24 \Omega / \square$. На рис. 1 представлен КРС-спектр синтезированной пленки. Спектр состоит из четырех главных линий: $D\left(1330 \mathrm{~cm}^{-1}\right), D^{\prime}\left(1616 \mathrm{~cm}^{-1}\right)$,
$G\left(1579 \mathrm{~cm}^{-1}\right)$ и $G^{\prime}\left(2660 \mathrm{~cm}^{-1}\right)$. Линию $G^{\prime}$ часто называют $2 D$-пиком (см., например, [2]). Первые две линии рассеяния возникают из-за наличия дефектов в гексагональной структуре $s p^{2}$-атомов, $G$-линия связана с продольной модой колебаний атомов углерода, а $G^{\prime}$ является линией КРС второго порядка на граничных фононах зоны Бриллюэна $[16,17]$. Известно, что отличительной особенностью спектра однослойного графена является интенсивная $G^{\prime}$-линия, которая описывается одной кривой Лоренца с полушириной $25 \mathrm{~cm}^{-1}$, при этом $I_{G^{\prime}} / I_{G}>1$, где $I_{G^{\prime}}$ и $I_{G}-$ интенсивности линий $G^{\prime}$ и $G$ соответственно [16]. При увеличении количества слоев $G^{\prime}$-линия преобразуется и представляет собой совокупность нескольких линий, сдвинутых относительно друг друга по частотной шкале. В результате ширина результирующей $G^{\prime}$-линии возрастает, а ее основной пик смещается в красную область. При этом существенно уменьшается его интенсивность относительно интенсивности $G$-линии [16]. $G^{\prime}$-линия полученного нами спектра описывается одной кривой Лоренца с полушириной $40 \mathrm{~cm}^{-1}$, при этом справедливо $I_{G^{\prime}} / I_{G}=0.7$. Частотный сдвиг $G^{\prime}$-линии на полученном спектре совпадает с частотным сдвигом $G^{\prime}$-линии графена [16]. Величина $I_{G^{\prime}} / I_{G}$, частотный сдвиг и полуширина $G^{\prime}$-линии в совокупности с наличием $D^{\prime}$-линии являются характерным признаком многослойного графена, между слоями которого присутствует вращательное смещение [16]. Отметим, что отношение интенсивности $D$-линии $\left(I_{D}\right)$ к интенсивности $G$-линии $\left(I_{G}\right)$ составляет 0.4. Это указывает на небольшое количество дефектов в графеновых слоях. Согласно [18], размер кристаллитов вдоль плоскостей графеновых слоев $L_{a}$ многослойного графена зависит от $I_{G} / I_{D}$ и выражается следующей формулой: $L_{a}[\mathrm{~nm}]=\left(2.4 \cdot 10^{-10}\right) \lambda^{4}\left(I_{G} / I_{D}\right)$, где $\lambda-$ длина волны излучения, возбуждающего КРС $[\mathrm{nm}]$. Из этой формулы можно рассчитать, что размер кристаллитов вдоль плоскостей графеновых слоев в исследуемой ЛИГ-пленке составляет $108 \mathrm{~nm}$.

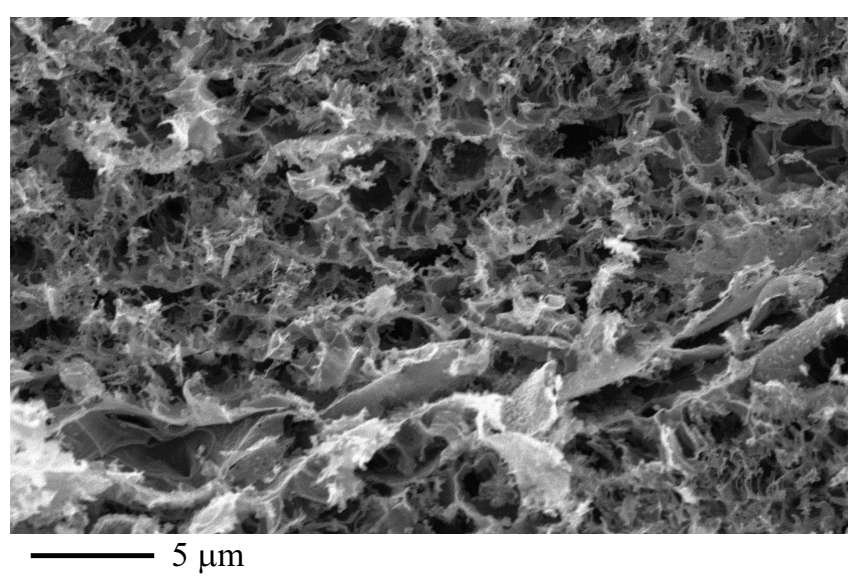

Рис. 2. Изображение поверхности лазерно-индуцированного графена, полученное с помощью сканирующего электронного микроскопа. 


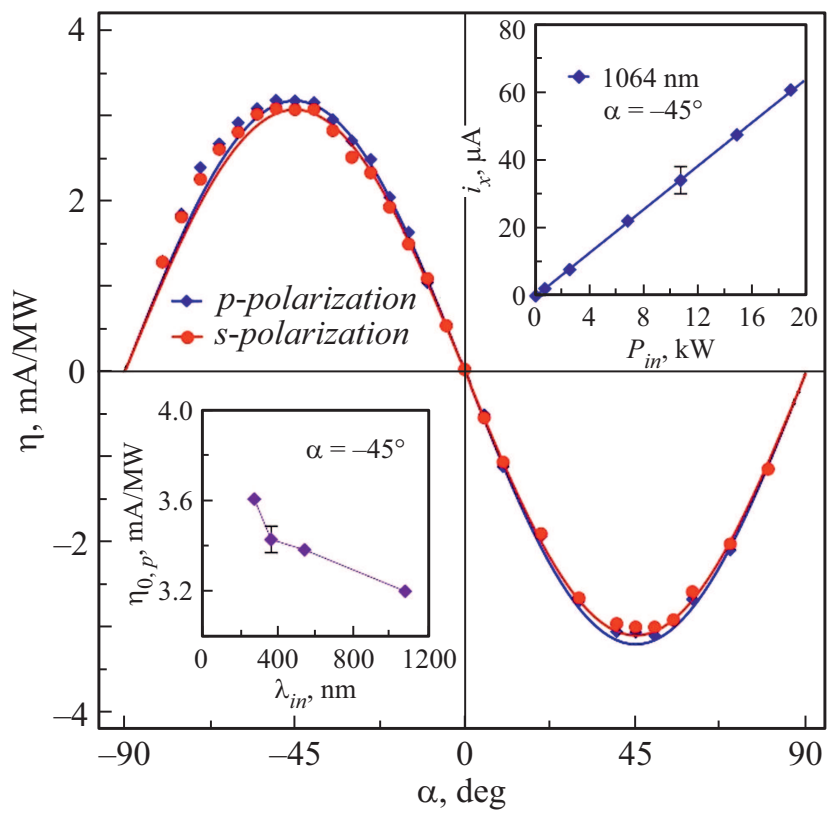

Рис. 3. Зависимость коэффициента преобразования $\eta$ лазерной мощности в фототок от угла падения $\alpha$ на длине волны $1064 \mathrm{~nm}$ при $p$ - и $s$-поляризациях падающего излучения на лазерно-индуцированный графен. На верхней вставке зависимость фототока лазерно-индуцированного графена от мощности $p$-поляризованного лазерного излучения на длине волны $1064 \mathrm{~nm}$ при угле падения $-45^{\circ}$. На нижней вставке зависимость коэффициента преобразования $\eta_{0, p}$ лазерной мощности в фототок в лазерно-индуцированном графене от длины волны $\lambda_{\text {in }}$ лазерного излучения.

Изображение поверхности синтезированной пленки, полученное с помощью сканирующего электронного микроскопа (рис. 2), показывает, что синтезированная пленка представляет собой пористую лепестковую структуру. Размер пор может достигать нескольких микрометров, а толщина лепестков составляет $\sim 100 \mathrm{~nm}$. Примечательно, что лепестки образуют связанную сеть, что обусловливает высокую проводимость пленки.

Эксперименты показали, что в синтезированных пленочных структурах при наклонном падении наносекундных лазерных импульсов происходит генерация импульсов фототока наносекундной длительности. Например, при $\lambda_{i n}=266 \mathrm{~nm}$ и $\tau_{i n}=9.4 \mathrm{~ns}$ импульсы фототока имеют длительность $\tau=14.5 \mathrm{~ns}$. Верхняя вставка на рис. 3 демонстрирует линейную зависимость фототока $i_{x}$ от импульсной мощности $P_{i n}$ лазера на длине волны $1064 \mathrm{~nm}\left(P_{i n}=E_{i n} / \tau_{i n}\right)$ при угле падения $-45^{\circ}$. Линейная зависимость $i_{x}$ от $P_{i n}$ сохраняется при возбуждении фототока излучением на длинах волн 532 , 354.7 и $266 \mathrm{~nm}$. Это позволяет ввести коэффициент преобразования $\eta$ лазерной мощности в фототок, определяемый по формуле $\eta=i_{x} / P_{i n}$. На рис. 3 представлена зависимость $\eta$ от угла падения $\alpha$ на длине волны $1064 \mathrm{~nm}$ при $p$ - и $s$-поляризациях падающего излучения. Из него видно, что при нормальном падении излу- чения на пленку фототок отсутствует, а при изменении знака угла падения направление фототока меняется. Полученные массивы экспериментальных данных при $p$ - и $s$-поляризациях падающего излучения хорошо аппроксимируются зависимостью $\eta_{p(s)}=-\eta_{0, p(s)} \sin 2 \alpha$ (где $\eta_{0, p} \approx \eta_{0, s} \approx 3.4 \mathrm{~mA} / \mathrm{MW}$ ), характерной для генерации фототока, возникающего за счет ЭУ в двумерных структурах (см., например, [12]). Обычно фототок ЭУ возникает одновременно с фототоком, обусловленным поверхностным фотогальваническим эффектом (ПФГЭ) [13,14]. Угловые зависимости $\eta_{p}(\alpha)$ и $\eta_{s}(\alpha)$, полученные при $p$ - и $s$-поляризациях соответственно, едва отличаются друг от друга. Это свидетельствует об отсутствии продольного фототока ПФГЭ, исчезающего при $s$-поляризации $[9,19]$, в синтезированных пленочных структурах.

Нижняя вставка на рис. 3 показывает экспериментально полученную зависимость $\eta_{0, p}$ от длины волны $\lambda_{i n}$ возбуждающего лазера. Видно, что с уменьшением $\lambda_{i n}$ (т.е. с увеличением энергии падающих квантов) коэффициент преобразования $\eta_{0, p}$ возрастает, что согласуется с данными, полученными для нанографитной пленки, синтезированной CVD-методом на кремниевых подложках $[9,20]$. Характер полученной зависимости $\eta_{0, p}\left(\lambda_{i n}\right)$ указывает на возможность применения ЛИГ для регистрации импульсов лазерного излучения в широком спектральном диапазоне.

Таким образом, с помощью непрерывного излучения углекислотного лазера на длине волны $10.6 \mu \mathrm{m}$ при плотности мощности $8 \mathrm{~W} / \mathrm{cm}^{2}$ и скорости сканирования луча $255 \mathrm{~mm} / \mathrm{s}$ на полиимидных пленках можно синтезировать пленочную структуру, состоящую из пористого графена. Под действием наносекундных лазерных импульсов в диапазоне длин волн $266-1064 \mathrm{~nm}$ в лазерноиндуцированном графене происходит генерация фототока, обусловленного эффектом увлечения. Лазерноиндуцированный графен может быть использован для создания быстродействующих фотоприемников для регистрации лазерных импульсов в широком спектральном диапазоне.

\section{Благодарности}

Авторы благодарны И.В. Редуто (Санкт-Петербургский национальный исследовательский Академический университет РАН) за помощь в проведении части экспериментов.

Эксперименты выполнялись с использованием оборудования Центра коллективного пользования УдмФИЦ УpO РAH.

\section{Финансирование работы}

Исследование выполнено за счет гранта Российского научного фонда (проект № 19-72-00071). 


\section{Конфликт интересов}

Авторы заявляют, что у них нет конфликта интересов.

\section{Список литературы}

[1] Вяткин А.Ф. // Письма в ЖТФ. 2019. Т. 45. В. 4. С. 49-51.

[2] Логинов А.Б., Божьев И.В., Бокова-Сирош С.Н., Образцова Е.Д., Исмагилов Р.Р., Логинов Б.А., Образцов А.Н. // ЖТФ. 2019. Т. 89. В. 11. С. 1756-1762.

[3] Lin J., Peng Z., Liu Y., Ruiz-Zepeda F., Ye R., Samuel E.L.G., Yacaman M.J., Yakobson B.I., Tour J.M. // Nature Commun. 2014. V. 5. P. 5714 (1-8).

[4] Lamberti A., Perrucci F., Caprioli M., Serrapede M., Fontana M., Bianco S., Ferrero S., Tresso E. // Nanotechnology. 2017. V. 28. P. 174002.

[5] Duy X.L., Peng Z., Li Y., Zhang J., Ji Y., Tour J.M. // Carbon. 2018. V. 126. P. $472-479$.

[6] In J.B., Hsia B., Yoo J.-H., Yoo J.-H., Hyun S., Carraro C., Maboudian R., Grigoropoulos C.P. // Carbon. 2015. V. 83. P. 144-155.

[7] Cai J., Lv C., Watanabe A. // J. Mater. Chem. A. 2016. V. 4. P. $1671-1679$.

[8] Ye R., James D.K., Tour J.M. // Adv. Mater. 2019. V. 31. P. e1803621.

[9] Obraztsov P.A., Mikheev G.M., Garnov S.V., Obraztsov A.N., Svirko Y.P. // Appl. Phys. Lett. 2011. V. 98. P. 091903.

[10] Zhu L., Huang Y., Yao Z., Quan B., Zhang L., Li J., Gu C., $X u$ X., Ren Z. // Nanoscale. 2017. V. 9. P. 10301-10311.

[11] Kovalev V.M., Miroshnichenko A.E., Savenko I.G. // Phys. Rev. B. 2018. V. 98. P. 165405.

[12] Берегулин Е.В., Воронов П.М., Иванов С.В., Копьев П.С., Ярошещкий И.Д. // Письма в ЖЭТФ. 1994. Т. 59. В. 2. C. $83-85$.

[13] Mikheev G.M., Saushin A.S., Styapshin V.M., Svirko Y.P. // Sci. Rep. 2018. V. 8. P. 8644.

[14] Михеев Г.М., Саушин А.С., Стяпшин В.М., Свирко Ю.П. // Письма в ЖТФ. 2018. Т. 44. В. 18. С. 84-93.

[15] Михеев Г.М., Могилева Т.Н., Попов А.Ю., Калюжный Д.Г. // Приборы и техника эксперимента. 2003. № 2. C. $101-107$.

[16] Ferrari A.C., Meyer J.C., Scardaci V., Casiraghi C., Lazzeri M., Mauri F., Piscanec S., Jiang D., Novoselov K.S., Roth S., Geim A.K. // Phys. Rev. Lett. 2006. V. 97. P. 187401.

[17] Malard L.M., Pimenta M.A., Dresselhaus G., Dresselhaus M.S. // Phys. Rep. 2009. V. 473. P. 51-87.

[18] Cançado L.G., Takai K., Enoki T., Endo M., Kim Y.A., Mizusaki H., Jorio A., Coelho L.N., Magalhães-Paniago R., Pimenta M.A. // Appl. Phys. Lett. 2006. V. 88. P. 163106.

[19] Михеев Г.М., Когай В.Я., Зонов Р.Г., Михеев К.Г., Могилева Т.Н., Свирко Ю.П. // Письма в ЖЭТФ. 2019. Т. 109. B. 11. C. $739-745$.

[20] Михеев Г.М., Зонов Р.Г., Образиов А.Н., Волков А.П., Свирко Ю.П. // Письма в ЖТФ. 2005. Т. 31. В. 3. С. 11-17. 